\title{
IMPROVING THE USE OF FRANS KAISIEPO AIRPORT THROUGH ALTERNATIVE ELECTION DEVELOPMENT OF REGIONAL POTENTIALS OF BIAK NUMFOR REGENCY (CASE STUDY: BIAK NUMFOR DISTRICT, PAPUA)
}

\author{
Muhammad Nur Roviq'), Uyuunul Mauidzoh ${ }^{2)}$, Eko Poerwanto ${ }^{3)}$ \\ Program Studi Teknik Industri Sekolah Tinggi Teknologi Adisutjipto Yogyakarta \\ Jl. Janti Blok-R Lanud Adisutjipto Yogyakarta \\ Email : ${ }^{1}$ farahzizy@gmail.com
}

\begin{abstract}
Frans Kaisiepo Airport is the airport with the first international status in the Papua region with the airport managing agency PT. Angkasa Pura I (Persero) and has runway specifications and airport facilities that are fairly good and complete. The airport is located in the Biak Numfor-Papua district, where the district has regional potential that can be developed to increase the utilization of the Frans Kaisiepo airport such as tourism, fisheries, industry and Biak Numfor as a place / space research facility. In this research, it is intended to choose alternative potential of the Biak Numfor district area to be developed in order to improve the utilization of the Frans Kaisiepo Biak Numforairport. In this study, the Analytical Hierarchy Process (AHP) method is used to choose the best alternative potential for the region from the existing potential areas, with the steps in the AHP are (1) Problem decomposition (2) Matrix preparation (3) Assessment /weighting for compare elements (4) Normalization (synstesis) of priorities and consistency tests and (5) Decision making / decision making. Then given suggestions for efforts to develop the potential of selected areas using SWOT analysis. The results of the priority assessment in this study, the final results for the selection of alternative potential areas that are expected to increase the use of Frans Kaisiepo airport are tourism potentials that have the highest priority weight of 0.379 , followed by fisheries potential with a priority weight of 0.318 . Next, the third and fourth priority sequentially are industry potential and space research facilities with a weight of 0.169 and 0.132 . From the results of the SWOT analysis, several efforts that can be made to develop the tourism potential of Biak Numfor Regency are as follows: (1) Optimizing management of tourism potential (2) Increasing tourism promotion efforts in Biak Numfor district (3) Increasing professional human resources to improve the tourism performance of the Biak Numfor district area.
\end{abstract}

Keywords : Regional Potential Development, Utilization of Frans Kaisiepo Airport, Analytical Hierarchy Process, SWOT analysis

\section{Pendahuluan}

Kabupaten Biak Numfor merupakan salah satu kabupaten yang terletak di Provinsi Papua. Kabupaten ini merupakan gugusan pulau yang berada di sebelah utara daratan pulau Papua atau lebih tepatnya berada di kawasan teluk cenderawasih dan berseberangan langsung dengan samudera pasifik. Kabupaten Biak Numfor dapat berperan sebagai penghubung maupun pintu masuk bagi negara-negara luar, seperti negara-negara yang berada di kawasan Asia Pasifik, Filiphina, Papua New Guinea, Australia, dan yang lainnya.Posisi tersebut menjadikan Kabupaten Biak Numfor sebagai 
salah satu wilayah/daerah yang strategis secara geografis. kabupaten Biak Numfor juga memiliki beberapa potensi daerah yang dapat menjadi unggulan dan jika dikembangkan maka dapat menjadi faktor dalam peningkatan pemanfaatan bandara Frans Kaisiepo, seperti potensi pariwisata, potensi perikanan, potensi industri juga sebagai sarana penelitian luar angkasa. (Sumber: https://biakkab.go.id/)

Bandara Frans Kaisiepo merupakan bandara dengan status Internasional pertama di wilayah Papua dengan badan pengelola bandar udaranya adalah PT. Angkasa Pura I (Persero) dan merupakan pintu gerbang di wilayah timur Indonesia khususnya provinsi Papua. Pada dasarnya bandara Frans Kaisepo merupakan bandar udara dengan spesifikasi landasan pacu dan fasilitas bandar udara yang terbilang lengkap dan cukup baik untuk melayani penerbangan rute Internasional maupun domestik. Lalu lintas angkutan udara di bandara Frans Kaisiepo Biak Numfor pada tahun 2013 sampai 2015 mengalami penurunan setiap tahunnya. Berdasarkan data Dirjen Perhubungan Udara RI pada rentang tahun 2013-2015, tingkat pergerakan pesawat, penumpang dan kargo di Bandara Frans Kaisiepo Biak Numfor diketahui seperti pada tabel 1.1 berikut:

Tabel 1 Data Lalu Lintas Angkutan Udara di Bandara Frans Kaisiepo (Sumber: Direktorat Jenderal Perhubungan Udara RI)

\begin{tabular}{|c|c|c|c|c|c|}
\hline \multicolumn{6}{|c|}{ BANDARA FRANS KAISIEPO } \\
\hline TAHUN & JENIS & DATANG & BERANGKAT & TRANSIT & LOKAL \\
\hline \multirow[t]{5}{*}{2013} & Pesawat & 5.298 Pergerakan & 5.308 Pergerakan & & 0 \\
\hline & Penumpang & 138.407 Orang & 146.845 Orang & 108.320 Orang & \\
\hline & Bagasi & $1.359 .076 \mathrm{Kg}$ & $1.359 .775 \mathrm{Kg}$ & & \\
\hline & Kargo & $644.576 \mathrm{Kg}$ & $541.375 \mathrm{Kg}$ & & \\
\hline & Pos & 660 & 718 & & \\
\hline \multirow[t]{5}{*}{2014} & Pesawat & 4.886 Pergerakan & 4.887 Pergerakan & & 0 \\
\hline & Penumpang & 127.058 Orang & 132.928 Orang & 72.602 Orang & \\
\hline & Bagasi & $1.142 .714 \mathrm{Kg}$ & $1.217 .473 \mathrm{Kg}$ & & \\
\hline & Kargo & $567.608 \mathrm{Kg}$ & $383.395 \mathrm{Kg}$ & & \\
\hline & Pos & 827 & 719 & & \\
\hline \multirow[t]{5}{*}{2015} & Pesawat & 2.203 Pergerakan & 2.205 Pergerakan & & 0 \\
\hline & Penumpang & 57.681 Orang & 62.041 Orang & 135.181 Orang & \\
\hline & Bagasi & $497.479 \mathrm{Kg}$ & $493.175 \mathrm{Kg}$ & & \\
\hline & Kargo & $272.536 \mathrm{Kg}$ & $152.251 \mathrm{Kg}$ & & \\
\hline & Pos & 197 & 62 & & \\
\hline
\end{tabular}

\section{Metodologi Penelitian}

Pengolahan data pada penelitian ini dilakukan secara kuantitatif dan kualitatif Penelitian ini dilakukan dengan dua tahap, yaitu menganalisis pemilihan pengembangan potensi daerah terbaik dengan menggunakan metode Analytical Hierarchy Process, yang kemudian dilakukan analisis saran strategi pengembangan terhadap potensi daerah terpilih dengan menggunakan metode SWOT.

a. Prosedur AHP meliputi tahapan-tahapan sebagai berikut:

1) Dekomposisi masalah/menyusun hierarchy

2) Penyusunan matriks;

3) Penilaian/pembobotan untuk membandingkan elemen-elemen;

4) Normalisasi (sintesis) dari prioritas dan uji konsistensi

5) Pengambilan/penetapan keputusan. 
Improving The Use Of Frans Kaisiepo Airport Through Alternative Election Development Of...

\section{b. Analisis SWOT}

Setelah didapatkan atau dipilih salah satu potensi daerah terbaik dari beberapa alternatif pemilihan potensi daerah yang ada dengan menggunakan metode Analytical Hierarchy Process, maka selanjutnya akan dilakukan analisis untuk mendapatkan strategi pengembangan potensi daerah terpilih tersebut dengan menggunakan analisis SWOT.

Dalam melakukan analisis SWOT, tahapan kegiatan yang dilakukan adalah dengan mengidentifikasi faktor-faktor Internal dan Eksternal dan kemudian dilakukan analisis data berdasarkan analisis strategi $(\mathrm{S}-\mathrm{O}),(\mathrm{S}-\mathrm{T}),(\mathrm{W}-\mathrm{O})$ dan $(\mathrm{W}-\mathrm{T})$ seperti pada gambar berikut ini :

\begin{tabular}{|c|c|c|}
\hline SW-OT & Kekuatan (S) & Kelemahan (W) \\
\hline Peluang (O) & $\begin{array}{ll}\text { Strategi SO: } \\
\text { - Strategi yang } \\
& \text { memaksimalkan } \\
& \text { kekuatan untuk } \\
& \text { memanfaatkan } \\
& \text { peluang yang ada, } \\
\text { - } & \text { Strategi agresif, } \\
\text { - } & \text { Keunggulan } \\
& \text { Komparatif. } \\
\end{array}$ & $\begin{array}{l}\text { Strategi WO: } \\
\text { - Strategi yang } \\
\text { meminimalkan } \\
\text { kelemahan untuk } \\
\text { memanfaatkan } \\
\text { peluang, } \\
\text { - Strategi orientasi } \\
\text { putar balik, } \\
\text { - Investasi/disvestasi. }\end{array}$ \\
\hline Ancaman (T) & $\begin{array}{l}\text { Strategi ST: } \\
\text { - Strategi yang } \\
\text { memaksimalkan } \\
\\
\text { kekuatan untuk } \\
\text { mengatasi } \\
\text { ancaman, } \\
\text { - Strategi } \\
\text { diversifikasi, } \\
\text { - Mobilisasi. }\end{array}$ & $\begin{array}{l}\text { Strategi WT: } \\
\text { - Strategi yang } \\
\text { meminimalkan } \\
\text { kelemahan untuk } \\
\text { mengatasi ancaman, } \\
\text { - Strategi defensif, } \\
\text { - } \\
\text { Kontrol } \\
\text { kerusakan/strategi } \\
\text { riskan. }\end{array}$ \\
\hline
\end{tabular}

Gambar 1 Matrix SWOT

\section{Hasil Dan Pembahasan}

Dalam pemilihan alternatif pengembangan potensi daerah Kabupaten Biak Numfor terdapat beberapa alternatif potensi daerah yang dapat dikembangkan dapat berkontribusi dalam peningkatan meningkatkan penggunaan bandara Frans Kaisiepo. Potensi tersebut adalah, Potensi Pariwisara, Potensi Perikanan, Potensi Industri dan Sarana Penelitian Antariksa. Sedangkan kriteria dan sub kriteria penentuan sistem pendukung keputusan sebagai berikut :

a. Kriteria Aspek Lingkungan

1) Penggunaa Lahan (L1)

2) Adanya Sarana dan Prasarana Baru (L2)

3) Ada Atau Tidaknya Sumber Daya Utama Potensi Daerah (L3)

b. Kriteria Aspek Sosial

1) Dukungan Masyarakat Sekitar (S1)

2) Terbukanya Lapangan Kerja Baru (S2)

3) Meningkatkan Kunjungan Daerah/Menarik Minat Pasar (S3)

c. Kriteria Aspek Ekonomi

1) Pertumbuhan Ekonomi Daerah (E1)

2) Mendatangkan Minat Investor (E2)

Struktur Hirarki hirarki Analytical Hierarchy Process (AHP) yang digunakan dalam pemilihan Alternatif Pengembangan Potensi Daerah Kabupaten Biak Numfor dapat dilihat pada gambar 2 . 


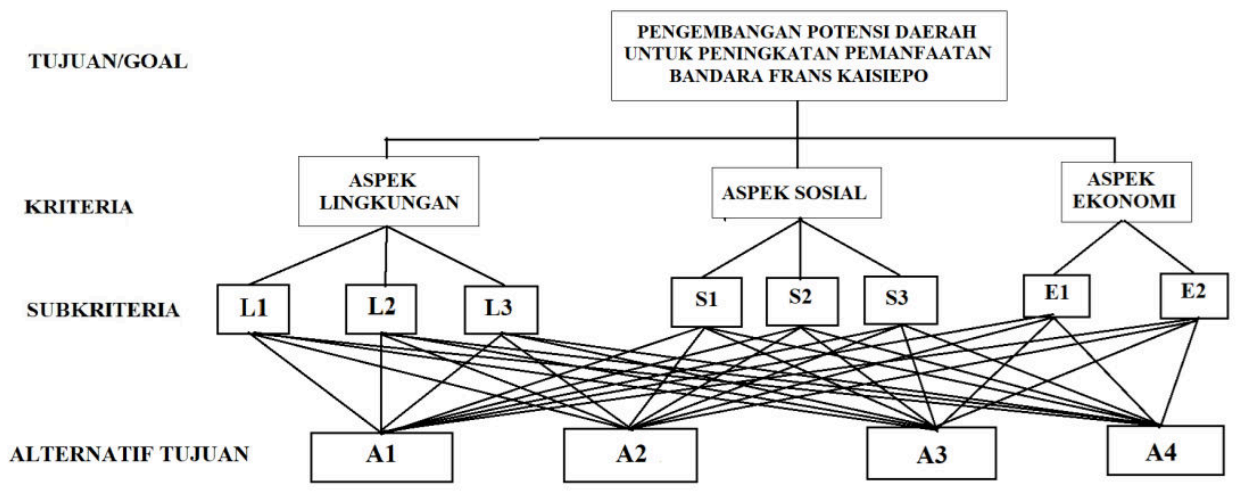

Gambar 2 Hirarki Pemilihan Alternatif Pengembangan Potensi Daerah

\subsection{Prioritas Penilaian Perbandingan Berpasangan Tiap Elemen}

Untuk dapat menentukan nilai perbandingan berpasangan, maka akan digunakan skala penilaian perbandingan berpasangan seperti pada tabel berikut :

Tabel 2 Penilaian Perbandingan Berpasangan

\begin{tabular}{|l|c|c|c|}
\hline \multicolumn{1}{|c|}{ Deskripsi } & $\begin{array}{c}\text { Kriteria } \\
\text { A }\end{array}$ & $\begin{array}{c}\text { Kriteria } \\
\text { B }\end{array}$ & B/A \\
\hline A sama pentingnya dengan B & 1 & 1 & 1 \\
\hline A sedikit lebih penting dari B & 3 & 1 & $1 / 3$ \\
\hline A secara signifikan lebih penting dari B & 5 & 1 & $1 / 5$ \\
\hline A jauh lebih penting dari B & 7 & 1 & $1 / 7$ \\
\hline A secara absolut lebih penting dari B & 9 & 1 & $1 / 9$ \\
\hline
\end{tabular}

\section{a. Menentukan Bobot Masing-masing Kriteria}

Perhitungan Bobot Rata-rata (Geometric Mean) Tiap Kriteria. Menghitung bobot rata-rata (Geometric Mean) adalah sebagai berikut :

$$
\mathrm{GM}=(\mathrm{x} 1, \mathrm{x} 2, \mathrm{x} 3, \ldots \mathrm{xn})^{1 / n}
$$

Dimana: GM = Geometric Mean

$\mathrm{x} 1, \mathrm{x} 2, \mathrm{x} 3, \ldots . . \mathrm{xn}=$ Bobot penilaian $\mathrm{ke} 1,2,3, \ldots \ldots$

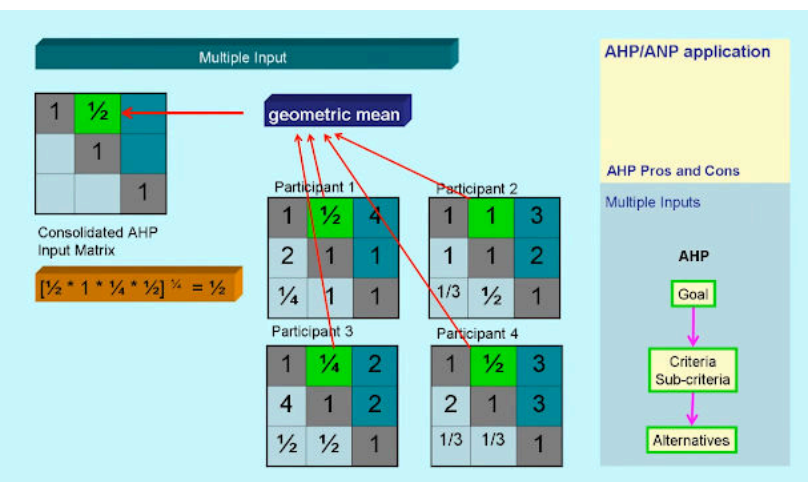

Gambar 3 Menentukan Nilai Geometric Mean 
Improving The Use Of Frans Kaisiepo Airport Through Alternative Election Development Of...

Hasil perhitungan geometric mean dapat dilihat pada tabel 3 berikut ini.

Tabel 3 Hasil Geometric Mean Tiap Kriteria

\begin{tabular}{|c|c|c|c|}
\hline KRITERIA & $\begin{array}{c}\text { Aspek } \\
\text { Lingkungan }\end{array}$ & Aspek Sosial & $\begin{array}{c}\text { Aspek } \\
\text { Ekonomi }\end{array}$ \\
\hline Aspek Lingkungan & $\mathbf{1 , 0 0}$ & 0,69 & 0,28 \\
\hline Aspek Sosial & 1,44 & $\mathbf{1 , 0 0}$ & 0,32 \\
\hline Aspek Ekonomi & 3,56 & 3,11 & $\mathbf{1 , 0 0}$ \\
\hline Jumlah & 6,00 & 4,80 & 1,60 \\
\hline
\end{tabular}

\section{b. Normalisasi Bobot Kepentingan Tiap Kriteria}

Apabila proses pembobotan nilai telah selesai, langkah selanjutnya adalah penyusunan matriks berpasangan untuk melakukan normalisasi bobot tingkat kepentingan pada tiap-tiap elemen pada hirarki masing-masing. Normalisasi (sintesis) ini menghasilkan presentase bobot prioritas relatif menyeluruh untuk masing-masing kriteria.

Tabel 4 Normalisasi Bobot Penilaian Tiap Kriteria

\begin{tabular}{|c|c|c|c|c|}
\hline KRITERIA & $\begin{array}{c}\text { Aspek } \\
\text { Lingkungan }\end{array}$ & $\begin{array}{c}\text { Aspek } \\
\text { Sosial }\end{array}$ & $\begin{array}{c}\text { Aspek } \\
\text { Ekonomi }\end{array}$ & $\begin{array}{c}\text { Bobot } \\
\text { Prioritas }\end{array}$ \\
\hline $\begin{array}{c}\text { Aspek } \\
\text { Lingkungan }\end{array}$ & 0,167 & 0,144 & 0,175 & 0,162 \\
\hline Aspek Sosial & 0,240 & 0,208 & 0,201 & 0,216 \\
\hline Aspek Ekonomi & 0,593 & 0,647 & 0,624 & 0,621 \\
\hline Jumlah & 1,000 & 1,000 & 1,000 & 1,000 \\
\hline
\end{tabular}

\section{c. Menentukan Bobot Masing-masing Sub Kriteria}

Tabel 5 Penilaian Perbandingan Berpasangan Tiap Subkriteria Aspek Lingkungan

\begin{tabular}{|c|c|c|c|}
\hline PILIHAN & L1 & L2 & L3 \\
\hline L1 & $\mathbf{1 , 0 0}$ & 1,44 & 0,36 \\
\hline L2 & 0,69 & $\mathbf{1 , 0 0}$ & 0,25 \\
\hline L3 & 2,76 & 3,98 & $\mathbf{1 , 0 0}$ \\
\hline Jumlah & 4,45 & 6,42 & 1,61 \\
\hline
\end{tabular}

Tabel 6 Normalisasi Bobot Niliai Kepentingan Subkriteria Aspek Lingkungan

\begin{tabular}{|c|c|c|c|c|}
\hline PILIHAN & L1 & L2 & L3 & Bobot Prioritas \\
\hline L1 & 0,22 & 0,22 & 0,22 & 0,225 \\
\hline L2 & 0,16 & 0,16 & 0,16 & 0,156 \\
\hline L3 & 0,62 & 0,62 & 0,62 & 0,620 \\
\hline Jumlah & 1,00 & 1,00 & 1,00 & 1,000 \\
\hline
\end{tabular}


Tabel 7 Penilaian PerbandinganBberpasangan Tiap Subkriteria Aspek Sosial

\begin{tabular}{|c|c|c|c|}
\hline PILIHAN & S1 & S2 & S3 \\
\hline S1 & $\mathbf{1 , 0 0}$ & 2,47 & 3,00 \\
\hline S2 & 0,41 & $\mathbf{1 , 0 0}$ & 1,44 \\
\hline S3 & 0,33 & 0,69 & $\mathbf{1 , 0 0}$ \\
\hline Jumlah & 1,74 & 4,16 & 5,44 \\
\hline
\end{tabular}

Tabel 8 Normalisasi Bobot Kepentingan Subkriteria Aspek Sosial

\begin{tabular}{|c|c|c|c|c|}
\hline PILIHAN & S1 & S2 & S3 & Bobot Prioritas \\
\hline S1 & 0,575 & 0,593 & 0,551 & 0,573 \\
\hline S2 & 0,233 & 0,240 & 0,265 & 0,246 \\
\hline S3 & 0,192 & 0,167 & 0,184 & 0,181 \\
\hline Jumlah & 1,000 & 1,000 & 1,000 & 1,000 \\
\hline
\end{tabular}

Tabel 9 Penilaian Perbandingan Berpasangan Tiap Subkriteria Aspek Ekonomi

\begin{tabular}{|c|c|c|}
\hline PILIHAN & E1 & E2 \\
\hline E1 & $\mathbf{1 , 0 0}$ & 2,92 \\
\hline E2 & 0,34 & $\mathbf{1 , 0 0}$ \\
\hline Jumlah & 1,34 & 3,92 \\
\hline
\end{tabular}

Tabel 10 Normalisasi Bbobot Kepentingan Subkriteria Aspek Ekonomi

\begin{tabular}{|c|c|c|c|}
\hline PILIHAN & E1 & E2 & Bobot Prioritas \\
\hline E1 & 0,745 & 0,745 & 0,745 \\
\hline E2 & 0,255 & 0,255 & 0,255 \\
\hline Jumlah & 1,000 & 1,000 & 1,000 \\
\hline
\end{tabular}

\subsection{Penentuan Bobot Nilai Akhir Tiap Alternatif}

Setelah diketahui bobot masing-masing alternatif berdasarkan subkriteria yang ada, maka tahapan selanjutnya adalah pemberian bobot keseluruhan untuk masingmasing alternatif. 
Improving The Use Of Frans Kaisiepo Airport Through Alternative Election Development Of...

Tabel 11 Bobot Penilaian Keseluruhan Alternatif

\begin{tabular}{|c|r|c|c|c|c|}
\hline $\begin{array}{c}\text { Kriteria dan } \\
\text { Subkriteria }\end{array}$ & $\begin{array}{c}\text { Bobot Kriteria \& } \\
\text { Subkriteria }\end{array}$ & Al & A2 & A3 & A4 \\
\hline Aspek Lingkungan & 0,162 & & & & \\
\hline L1 & 0,036 & 0,098 & 0,128 & 0,305 & 0,470 \\
\hline L2 & 0,025 & 0,120 & 0,197 & 0,244 & 0,439 \\
\hline L3 & 0,100 & 0,271 & 0,271 & 0,188 & 0,271 \\
\hline Aspek Sosial & 0,216 & & & & 0,073 \\
\hline S1 & 0,124 & 0,540 & 0,260 & 0,127 & 0,177 \\
\hline S2 & 0,053 & 0,584 & 0,162 & 0,078 & \\
\hline S3 & 0,039 & 0,315 & 0,135 & 0,440 & 0,110 \\
\hline Aspek Ekonomi & 0,621 & & & & 0,067 \\
\hline E1 & 0,463 & 0,387 & 0,387 & 0,158 & 0,146 \\
\hline E2 & 0,158 & 0,354 & 0,354 & 0,146 & 0,132 \\
\hline $\begin{array}{c}\text { Bobbot } \\
\text { Keseluruhan }\end{array}$ & & 0,379 & 0,318 & 0,169 & \\
\hline
\end{tabular}

Berdasarkan perhitungan pada bobot penilaian akhir untuk tiap alternatif pilihan, maka didapatkan hasil akhir bahwa alternatif 1 menempati urutan pertama dengan bobot sebesar 0,379, pada urutan kedua ditempati oleh alternatif 2 dengan bobot sebesar 0,318, diikuti dengan alternatif 3 dan 4 dengan bobot alternatif 3 sebesar 0,169 dan 0,132 untuk alternatif 4 .

\subsection{Analisa Strategi Pengembangan Potensi Pariwisata Biak Numfor}

Dari hasil perhitungan bobot alternatif menggunakan Analytical Hierarchy Process (AHP) diperoleh bobot tertinggi pada alternatif 1 yaitu potensi pariwisata. Adapun analisa strategi pengembangan potensi pariwisata daerah kabupaten Biak Numfor dapat dilihat pada tabel 12 berikut ini. 


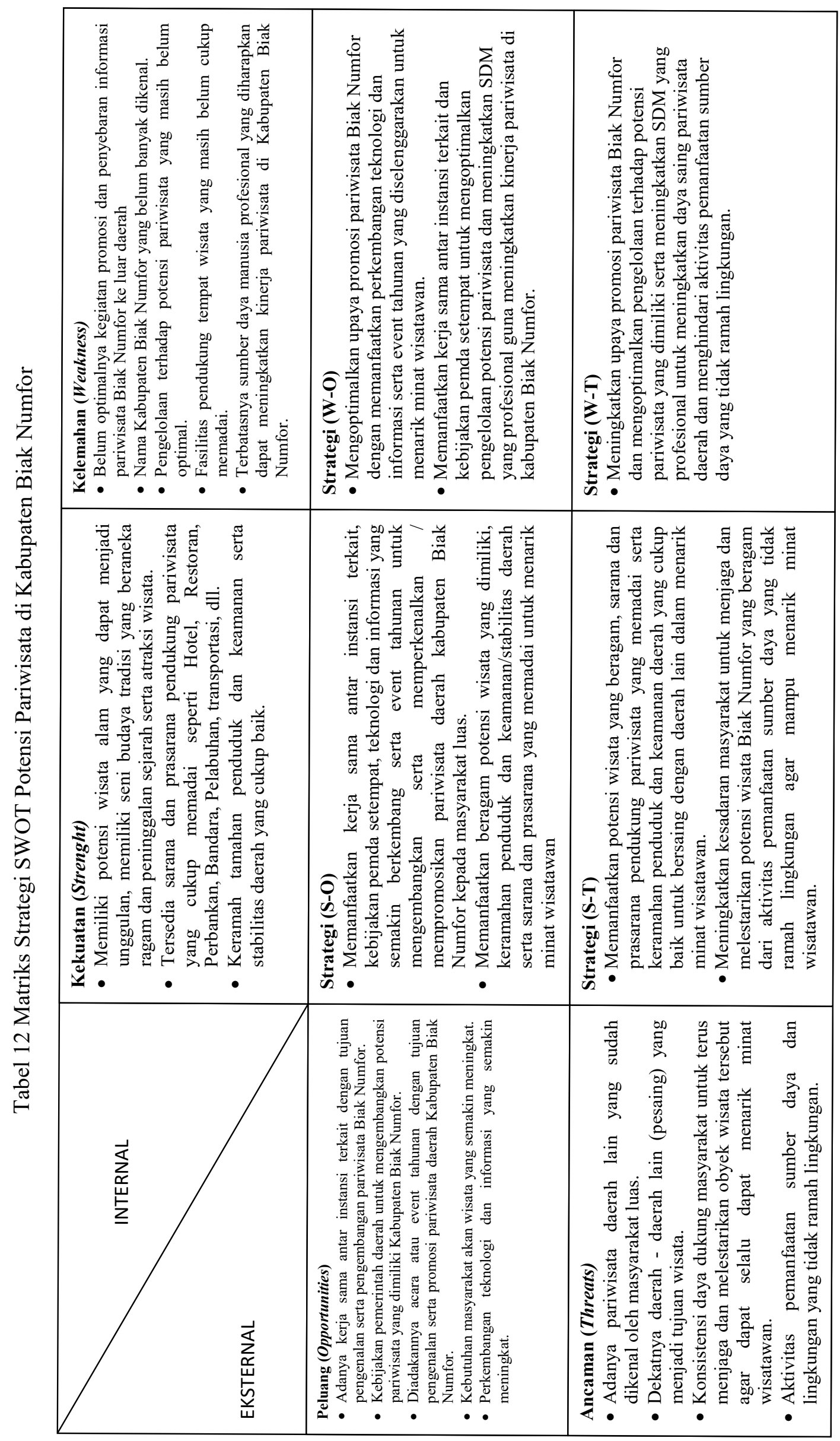


Upaya yang dapat dilakukan untuk mengembangkan potensi pariwisata kabupaten Biak Numfor adalah sebagai berikut :

1) Mengoptimalkan pengelolaan terhadap potensi pariwisata yang dimiliki.

2) Meningkatkan upaya promosi pariwisata daerah kabupaten Biak Numfor.

3) Meningkatkan sumber daya manusia yang profesional untuk meningkatkan kinerja pariwisata daerah kabupaten Biak Numfor

\section{Kesimpulan}

Berdasarkan hasil analisis yang telah dilakukan, maka dapat diambil kesimpulan sebagai berikut:

1) Diurutan pertama, potensi daerah dengan prioritas pengembangan tertinggi adalah alternatif A1 yaitu potensi Pariwisata yang memiliki bobot nilai sebesar 0,379. Alternatif kedua adalah alternatif A2 yaitu potensi Perikanan yang memiliki bobot nilai sebesar 0,318. Alternatif ketiga adalah alternatif A3 yaitu potensi Industri yang memiliki bobot nilai sebesar 0,169. Alternatif keempat adalah alternatif A4 yaitu sebagai Sarana Penelitian Antariksa yang memiliki bobot nilai sebesar 0,132.

2) Upaya yang dapat dilakukan untuk mengembangkan Potensi Pariwisata Kabupaten Biak Numfor adalah mengoptimalkan pengelolaan terhadap Potensi Pariwisata yang dimiliki, meningkatkan upaya promosi pariwisata daerah Kabupaten Biak Numfor dan meningkatkan sumber daya manusia yang profesional untuk meningkatkan kinerja pariwisata daerah Kabupaten Biak Numfor.

\section{Daftar Pustaka}

[1] Menteri Kebudayaan dan Pariwisata. (2009). Undang-Undang Republik Indonesia Nomor 10 Tahun 2009 tentang Kepariwisataan. Jakarta

[2] Direktorat Jenderal Otonomi Daerah. (2009). Undang-Undang Republik Indonesia Nomor 32 Tahun 2004 tentang Pemerintahan Daerah, Jakarta

[3] Kementerian Kelauatan dan Perikanan .(2009). Undang-Undang Republik Indonesia No.45 Tahun 2009. Jakarta

[4] (LAPAN), L. P. (2015). Rencana Strategis Tahun 2015-2019 Pusat Sains Antariksa. Bandung: Lembaga Penerbangan dan Antariksa Nasional (LAPAN).

[5] Achmad Rochani, N. M. (2006). KABUPATEN BIAK NUMFOR: Upaya Bangkit Dari Keterpurukan. Makassar: Pustaka Refleksi.

[6] Asmarani, A. D. (2010). Strategi kebijakan pembangunan daerah Kabupaten Klaten pendekatan analisis swot dan AHP (Doctoral dissertation, Universitas Indonesia. Fakultas Ekonomi).

[7] Wijaya, B., \& Dwi Atmanti, H. (2006). Analisis pengembangan wilayah dan sektor potensial guna mendorong pembangunan di Kota Salatiga. Jurnal Dinamika Pembangunan (JDP), 3(Nomor 2), 101-118.

[8] COLABORATIVE DESTINATION DEVELOPMENT 2018. (6AD, January). Retrieved June 1, 2019, from http://franskaisiepo-airport.co.id/id.

[9] BAPPEDA, Biak. Numfor. (n.d.). Retrieved from http://biakkab.go.id/

[10] Dampak Pariwisata Terhadap Lingkungan, http://stipram.ac.id/2012/index.php

[11] Data Kawasan Konservasi TWP Pulau Padaido. (n.d.). Retrieved November 26, 2019, from $\quad$ http://kkji.kp3k.kkp.go.id/index.php/basisdata-kawasankonservasi/details/1/103. 
[12] Sulistiyani, E., Amir, M. I. H., Yusuf, K. R., \& Nasrullah, D. I. (2017). Implementasi Metode Analytical Hierarchy Process (AHP) Sebagai Solusi Alternatif Dalam Pemilihan Supplier Bahan Baku Apel Di PT. Mannasatria Kusumajaya. Technology Science and Engineering Journal, 1(2).

[13] Fatmawati, N. S. (-). Peluang Pemanfaatan Bandara Frans Kaisiepo Biak Sebagai AEROSPACEPORT Di Indonesia. Kajian Kebijakan Penerbangan dan Antariksa, 18.

[14] Fuadati, S. R. (2018). Analisis Swot Untuk Pengembangan Potensi Dan Peluang Pasar Kabupaten Blitar Yang Bertumpu Pada Potensi Sumberdaya Alam. EKUITAS (Jurnal Ekonomi dan Keuangan), 12(2), 252-273.

[15] Suara Papua. (2018, January 12). Menelisik Pulau Biak Sebagai Pusat Peluncuran Satelit. Retrieved November 26, 2019, from https://suarapapua.com/2017/08/05/menelisik-pulau-biak-sebagai-pusatpeluncuran-satelit/.

[16] Hubud. (n.d.). Navigasi Penerbangan. Retrieved November 26, 2019, from http://hubud.dephub.go.id/.

[17] Indonesia, K. K. (2017). Review Masterplan Dan Bisnis Plan Pembangunan Sentra Kelautan Dan Perikanan Terpadu (Skpt) Kabupaten Biak Numfor. Jakarta: Kementrian Kelautan dan Perikanan Republik Indonesia.

[18] Industri, D. T. (2018). Perancangan Teknik Industri-II. Yogyakarta: Sekolah Tinggi Teknologi Adisutjipto.

[19] Data Kawasan Konservasi TWP Pulau Padaido. (n.d.). Retrieved November 26, 2019, from http://kkji.kp3k.kkp.go.id/index.php/basisdata-kawasankonservasi/details/1/103.

[20] Khuzaini, K., \& Suwitho, S. (2018). Analisis Swot Daya Dukung Daerah Terhadap Pengembangan Kawasan Industri Kabupaten Blitar. EKUITAS (Jurnal Ekonomi dan Keuangan), 11(2), 193-218.

[21] Adam, L., \& Surya, T. A. (2013). Kebijakan pengembangan perikanan berkelanjutan di indonesia. Jurnal Ekonomi dan Kebijakan Publik, 4(2), 195-211.

[22] Mujtahid, I. M. (2012). Strategi Pembangunan Daerah di Provinsi Bengkulu: Indonesia Menuju MDGs 2015.

[23] Numfor, B. K. (2018). Biak Numfor Dalam Angka 2018. Biak Kota: BPS Kabupaten Biak Numfor.

[24] Numfor, D. P. (n.d.). https://pariwisata.biakkab.go.id/. Retrieved from https://pariwisata.biakkab.go.id/

[25] PPN/BAPPENAS, K. (2016). Ringkasan Kajian Strategi Industrialisasi Perikanan Untuk Mendukun Pembangunan Ekonomi Wilayah. Pembangunan Ekonomi Wilayah Berbasis Industrialisasi Perikanan, 22.

[26] Prawaka, M. D. (2016). Analisis Strategi Kebijakan Pembangunan Daerah Kota Bandar Lampung (Pendekatan Analisis SWOT dan AHP).

[27] Suara Papua. (2018, January 12). Menelisik Pulau Biak Sebagai Pusat Peluncuran Satelit. Retrieved November 26, 2019, from https://suarapapua.com/2017/08/05/menelisik-pulau-biak-sebagai-pusatpeluncuran-satelit/.

[28] Tumada, L. O. (2012). Analisis Strategis Pembangunan Kabupaten Muna. Jakarta: Magister Fakultas Ekonomi Universitas Indonesia. 
[29] Wibowo, P. A. S., \& Ma'rif, S. (2014). Alternatif Strategi Pengembangan Desa Rahtawu Sebagai Daya Tarik Wisata di Kabupaten Kudus. Jurnal Wilayah dan Lingkungan, 2(3), 245-256.

[30] Wibowo, A. S., \& Priyono, K. D. (2017). Analisis Potensi Pengembangan Objek Wisata Alam Kabupaten Kolaka Provinsi Sulawesi Tenggara (Doctoral dissertation, Universitas Muhammadiyah Surakarta). 
Muhammad Nur Roviq, Uyuunul Mauidzoh, Eko Poerwanto 